\title{
Current Status of Immunotherapy for Lung Cancer and Future Perspectives
}

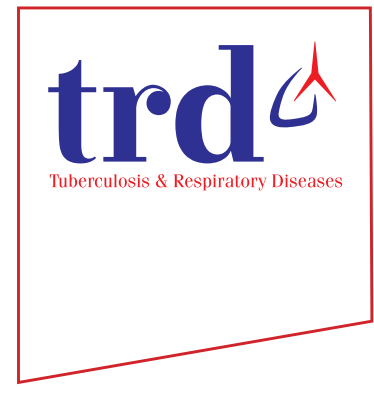

\author{
Ho Cheol Kim, M.D. ${ }^{1}$ (i) and Chang-Min Choi, M.D., Ph.D. ${ }^{1,2}$ (i] \\ Departments of ${ }^{1}$ Pulmonary and Critical Care Medicine and ${ }^{2}$ Oncology, Asan Medical Center, University of Ulsan College of \\ Medicine, Seoul, Korea
}

Lung cancer remains the most common cause of cancer-related deaths worldwide. Although there are many possible treatments, including targeted therapies such as epidermal growth factor receptor tyrosine kinase inhibitors and anaplastic lymphoma kinase inhibitors, new therapeutic strategies are needed to improve clinical outcomes. Immunotherapy through the use of immune checkpoint inhibitors has provided one of the most important breakthroughs in the management of solid tumors, including lung cancers, and has shown promising results in numerous clinical trials. This review will present the current status of immunotherapy for lung cancer and future perspectives on these treatments.

Keywords: Lung Neoplasms; Immunotherapy; Prognosis; Survival

\section{Introduction}

Lung cancer is still the leading cause of cancer-related mortality worldwide. In Korea, 17,980 patients died from lung cancer in $2017^{1}$. The characteristics of these patients have changed over time in Korea, as in Western countries, with increases seen in the proportion of adenocarcinomas, female cases, and early-stage lung cancer ${ }^{2-4}$. Much recent progress has been made in the treatment and management of lung cancer. The National Lung Screening Trial has reported that screening with low-dose computed tomography is associated with a reduced mortality ${ }^{5}$. In addition, since numerous molecular pathways have been found to play a role in lung cancer ${ }^{6}$,

Address for correspondence: Chang-Min Choi, M.D., Ph.D.

Department of Pulmonary and Critical Care Medicine, Asan Medical

Center, University of Ulsan College of Medicine, 88 Olympic-ro 43-gil,

Songpa-gu, Seoul 05505, Korea

Phone: 82-2-3010-5902, Fax: 82-2-3010-6968

E-mail:ccm@amc.seoul.kr

Received: May. 3, 2019

Revised: Jul. 2, 2019

Accepted: Aug. 1, 2019

Published online: Aug. 31, 2019

(9) It is identical to the Creative Commons Attribution Non-Commercial License (http://creativecommons.org/licenses/by-nc/4.0/). many targeted therapies have been developed and used in real practice ${ }^{7-9}$. However, most lung cancer patients experience acquired resistance to targeting drugs, which represents the most significant clinical hurdle for these treatments ${ }^{10}$.

There is growing evidence that interactions with the tumor environment and the immune system are associated with lung cancer initiation and progression ${ }^{11}$. Cancer immunotherapy development has focused on various ligands and receptors that inhibit or stimulate the immune system, with the most studied area being immune checkpoint inhibitors, including agents that target the anti-programmed death- 1 (PD-1) or programmed death-ligand 1 (PD-L1) molecules ${ }^{12-14}$. We here review the mechanisms underlying immune checkpoint inhibitor functions and the current evidence for the effectiveness of approved immune checkpoint inhibitor drugs in diverse clinical settings, i.e., monoclonal antibodies against the PD-1 receptor (nivolumab and pembrolizumab) and its ligand PD-L1 (atezolizumab and durvalumab). In addition, we briefly discuss future perspectives for immunotherapies directed against lung cancer.

\section{Mechanisms Underlying Anti-cancer Immune Responses and Immune Checkpoint Inhibitor Function}

Antitumor immune responses are known as the cancerimmunity cycle which involves the release of cancer antigens, cancer antigen presentation (via antigen-presenting cells), 
trafficking of $\mathrm{T}$ cells to tumors, infiltration of tumors by $\mathrm{T}$ cells, recognition of cancer cells by $\mathrm{T}$ cells, and killing of cancer cells (Figure 1$)^{15,16}$. Each step of this cycle requires the regulation of numerous factors to maintain the delicate balance between immune activity and autoimmunity ${ }^{17}$.

To prevent autoimmunity, the activation and proliferation of T lymphocytes are regulated by immune checkpoint molecules under normal circumstances ${ }^{18}$. The best-characterized checkpoint pathways to date are cytotoxic T-lymphocyteassociated antigen 4 and PD- $1^{19}$. Crucially, cancer cells can express ligands that stimulate these checkpoint pathways and inhibit T-cell activation ${ }^{20}$. For example, PD-L1 expression has been detected in various solid tumors including lung cancer where it enables the cancer cells to evade immune respons$\mathrm{es}^{21-23}$. Thus, it was proposed that treatments that inhibit immune checkpoint pathways could potentially restore the T-cell response to certain tumors ${ }^{24}$, and there is growing evidence for this in advanced non-small cell lung cancer (NSCLC). The mechanism of action of the immune checkpoint inhibitors is summarized in Figure 2. In addition, the immune checkpoint inhibitor agents that have been approved by the U.S. Food and Drug Administration (FDA) up to June 2019 are summarized in Table 1.

\section{Use of Immune Checkpoint Inhibitors as a Salvage Treatment in Previously Treated NSCLC}

The CheckMate 057 study of nonsquamous NSCLC cases that had progressed during or after platinum-based chemotherapy found that treatments with the nivolumab group of immune checkpoint inhibitors produced a more favorable overall survival outcome than therapies with the docetaxel group (median overall survival, 12.2 months vs. 9.4 months; $\mathrm{p}=0.002)^{25}$. The CheckMate 017 study reported that the median overall survival was significantly better with the nivolumab group than the docetaxel group (9.2 months vs. 6.0 months, $\mathrm{p}<0.001)$ among patients with advanced, and previously treated, squamous cell carcinoma ${ }^{26}$.

In the prior KEYNOTE-010 study involving patients with a PD-L1 expression level $>1 \%$, the median overall survival in the group treated with the immune checkpoint inhibitor pembrolizumab was significantly greater than the docetaxel treatment

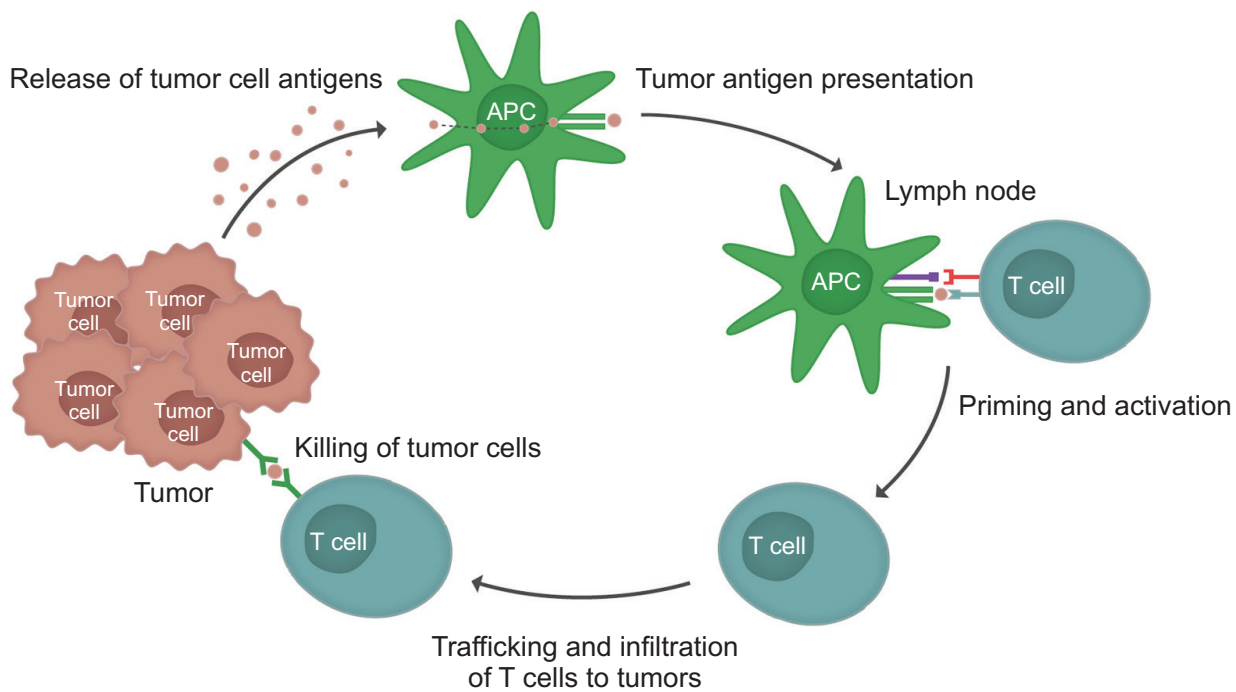

A

PD-1/PD-L1 pathway to suppress the immune response

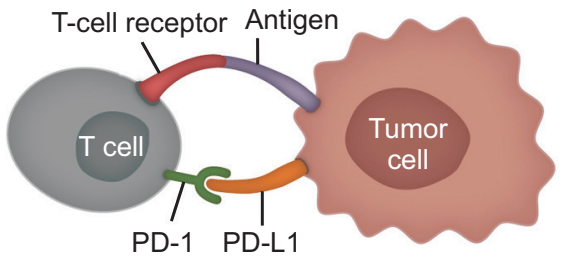

B Immunotherapy blockade PD-1/PD-L1 pathway and activate immune response

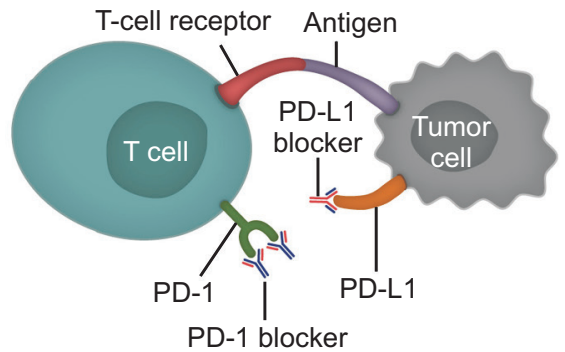

Figure 1. Mechanism underlying anticancer immune responses.
Figure 2. Mechanism of action of immune checkpoint inhibitors. (A) PD-1/ PD-L1 pathway to suppress the immune response. (B) Immunothearpy blockade PD-1/PD-L1 pathway and activate immune response. PD-1: programmed death-1; PD-L1: programmed deathligand 1 . 
Table 1. Indications for the use of current U.S. FDA-approved immune checkpoint inhibitors in lung cancer patients

\begin{tabular}{|c|c|c|c|c|}
\hline Agent & Indication & Line & Usage & Biomarker \\
\hline \multirow[t]{2}{*}{ Nivolumab } & Metastatic NSCLC* & 2nd line & Monotherapy & Any \\
\hline & Metastatic SCLC & 3rd line & Monotherapy & Any \\
\hline \multirow[t]{5}{*}{ Pembrolizumab } & Metastatic nonsquamous NSCLC ${ }^{\dagger}$ & 1st line & Combination with pemetrexed and platinum & \\
\hline & Metastatic squamous NSCLC & lst line & Combination with carboplatin and paclitaxel & Any \\
\hline & Stage III NSCLC ${ }^{\dagger}$ or metastatic NSCLC ${ }^{\dagger}$ & 1st line & Monotherapy & PD-Ll $\geq 1 \%$ \\
\hline & Metastatic NSCLC* & 2nd line & Monotherapy & PD-L1 $121 \%$ \\
\hline & Metastatic SCLC & 3rd line & Monotherapy & Any \\
\hline \multirow[t]{3}{*}{ Atezolizumab } & Metastatic non-squamous NSCLC ${ }^{\dagger}$ & lst line & $\begin{array}{l}\text { Combination with bevacizumab, paclitaxel, } \\
\text { and carboplatin }\end{array}$ & Any \\
\hline & Metastatic NSCLC* & 2nd line & Monotherapy & Any \\
\hline & Extensive-stage SCLC & 1st line & Combination with carboplatin and etoposide & Any \\
\hline Durvalumab & Unresectable, stage III NSCLC ${ }^{\S}$ & 2nd line & Monotherapy & Any \\
\hline
\end{tabular}

*Patients with EGFR or ALK genomic tumor aberrations are required to have shown disease progression on an FDA-approved therapy for these aberrations. ${ }^{\dagger}$ Patients with no EGFR or ALK genomic tumor aberrations. "Stage III NSCLC patients who are not candidates for surgical resection or definite chemoradiation. ${ }^{.}$Unresectable, stage III NSCLC cases whose disease has not progressed following concurrent platinumbased chemotherapy and radiation therapy.

U.S. FDA: U.S. Food and Drug Administration; NSCLC: non-small lung cancer; SCLC: small cell lung cancer; PD-L1: programmed deathligand 1; EGFR: epidermal growth factor receptor; ALK: anaplastic lymphoma kinase.

group (10.4 months in the $2 \mathrm{mg} / \mathrm{kg}$ group vs. 8.5 months in the docetaxel group [p=0.0008] and 12.7 months in the $10 \mathrm{mg} / \mathrm{kg}$ group vs. 8.5 months in the docetaxel group $[\mathrm{p}<0.0001])^{27}$. In the previous OAK study of atezolizumab, previously treated NSCLC patients who were administered this immune checkpoint inhibitor also showed better overall survival compared with a docetaxel treatment group (median overall survival, 13.8 months vs. 9.6 months; $\mathrm{p}=0.0003$ ), regardless of the PDL1 expression profile on histology ${ }^{28}$.

\section{Immune Checkpoint Inhibitors as a First-Line Treatment for Metastatic NSCLC}

Unfortunately, nivolumab monotherapies have not produced progression-free survival benefits as a first-line treatment compared with platinum-based chemotherapy in patients with stage IV or recurrent NSCLC, with a PD-L1 expression level of $5 \%$ or more (CheckMate 026 study) ${ }^{29}$. However, the KEYNOTE-024 study has reported that firstline pembrolizumab monotherapy significantly improved the progression-free survival (median, 10.3 months vs. 6.0 months; $p<0.001$ ) and overall survival (median overall survival was not reached in either group, $\mathrm{p}=0.005$ ) compared with platinum-based chemotherapy in NSCLC patients with a PDL1 tumor proportion score of $50 \%$ or greater ${ }^{30}$. Recently, the KEYNOTE-042 study reported that first-line pembrolizumab monotherapy showed better overall survival compared with platinum-based chemotherapy in patients with a PD-L1 of $1 \%$ or greater (hazard ratio [HR], 0.69; $\mathrm{p}=0.0003$ in $\mathrm{PD}-\mathrm{Ll} \geq 50 \%$ group; HR, 0.77; $\mathrm{p}=0.0020$ in $\mathrm{PD}-\mathrm{Ll} \geq 20 \%$ group; and HR, 0.81 ; $\mathrm{p}=0.0018$ in $\mathrm{PD}-\mathrm{Ll} 1 \geq 1 \%$ group $)^{31}$.

Since conventional chemotherapy can induce potential immunogenic effects ${ }^{32,33}$, it was postulated that a combination of chemotherapy and immunotherapy might have synergistic effects. Indeed, in the KEYNOTE-189 study of patients with previously untreated metastatic nonsquamous NSCLC, the addition of pembrolizumab to the standard chemotherapy regimen produced significantly improved progressionfree survival and overall survival outcomes compared with chemotherapy alone (median progression-free survival, 8.8 months vs. 4.9 months; $\mathrm{p}<0.001$; and median overall survival, not reached vs. 11.3 months; $\mathrm{p}<0.001)^{34}$. In the KEYNOTE-407 study of patients with previously untreated metastatic squamous NSCLC, the combination of pembrolizumab to the cytotoxic chemotherapy regimen also resulted in better progression-free and overall survival compared with chemotherapy alone (median progression-free survival, 6.4 months vs. 4.8 months; $\mathrm{p}<0.001$; and median overall survival, 15.9 months vs. 11.3 months; $\mathrm{p}<0.001)^{35}$.

There is evidence that atezolizumab produces benefits as a first-line therapy. The IMpower 150 study of patients with metastatic non-squamous NSCLC reported that the combination of atezolizumab and bevacizumab with chemotherapy resulted in a better overall survival compared with a bevacizumab plus chemotherapy regimen (median overall survival, 19.2 months vs. 14.7 months; $\mathrm{p}=0.02)^{36}$. In the IMpower 133 
study, the addition of atezolizumab to the chemotherapy protocol as the first-line treatment of extensive-stage small-cell lung cancer also had a favorable impact on progression-free survival and overall survival (median progression-free survival, 5.2 months vs. 4.3 months; $\mathrm{p}=0.02$; and median overall survival, 12.3 months vs. 10.3 months; $\mathrm{p}=0.007)^{37}$.

\section{Immune Checkpoint Inhibitor Use in Other Clinical Settings}

A recent pilot study has reported that nivolumab may have a role as a neoadjuvant therapy in surgically resectable $\mathrm{NSCLC}^{38}$. In addition, Cottrell et al. ${ }^{39}$ have demonstrated that neoadjuvant nivolumab may have benefits in terms of major pathologic regression. Current clinical trials are investigating immune checkpoint inhibitors as adjuvant treatments in patients with resected NSCLC ${ }^{40}$. Durvalumab (Imfinzi) is a human monoclonal antibody that blocks the binding of PD-L1 to PD-1 and CD80. Among 709 patients in the PACIFIC trial with stage III NSCLC, and with no disease progression after two or more cycles of platinum-based chemoradiotherapy, 473 cases received durvalumab, and 236 received a placebo. The overall and progression-free survival rates were significantly better in the durvalumab group (median overall survival, not reached vs. 28.7 months; $\mathrm{p}=0.0025$; and median progression-free survival, 16.8 months vs. 5.6 months; $\mathrm{p}<0.001)^{41}$.

\section{Adverse Events from Treatments with Immune Checkpoint Inhibitors}

It has been shown that some immune checkpoint inhibitors can potentially damage self-antigens, and thereby harm normal tissues, which is termed an immune-related adverse event (irAE) ${ }^{42}$. While the precise mechanisms underlying the onset of irAEs have not been well understood, a disruption of the balance in immunologic homeostasis is suggested as a major cause ${ }^{43}$. IrAEs can affect various organs including the liver, pituitary, thyroid, skin, lung, and nervous system among others $^{44,45}$. Among these events, pulmonary toxicity including pneumonitis has been highlighted as a particularly serious complication as it can be fatal in some cases ${ }^{46,47}$. Although an early suspicion and treatment interruption are the mainstays of the management of such adverse events, immunosuppression with corticosteroids and/or other immunosuppressant are often used to treat irAEs ${ }^{48,49}$.

\section{Future Perspectives}

A number of clinical trials are currently ongoing to evaluate immune checkpoint inhibitors as either a monotherapy or in combination with other agents. Moreover, the possible mechanisms of resistance to immune checkpoint inhibitors have now been reported, including insufficient generation, inadequate function, and an impaired memory of tumorspecific $\mathrm{T}$ cells ${ }^{50,51}$. There is recent evidence that cancer cell may interact with extracellular matrix, stromal cells, and immune cells, known as the tumor microenvironment (TME) ${ }^{52}$. TMEs can provide a haven from immune responses, which is one of the important mechanisms of resistance to immune checkpoint inhibitors ${ }^{51}$. Many strategies have been suggested to overcome this ${ }^{53,54}$. There has also been a growing number of studies on immunotherapies that do not use immune checkpoint inhibitors, one of which is chimeric antigen receptor (CAR) T-cell therapy ${ }^{55}$. CAR molecules are constructed from various protein segments that include an antigen-binding region and stimulatory domains, and CAR T-cell therapy is one of the adoptive T-cell therapies. It has been suggested that CAR-modified T cells may possibly be engineered to express synthetic receptors that will attach to tumor cells and destroy them $^{56}$.

\section{Conclusion}

Since the U.S. FDA has approved the use of four different immune checkpoint inhibitors for clinical use, these agents have become important treatment options for patients with lung cancer. In Korea, the Health Insurance Review and Assessment Service has approved insurance coverage for the immune checkpoint inhibitors nivolumab, pembrolizumab, and atezolizumab as salvage treatments for patients with previously treated NSCLC. Although some of these cases have experienced "immune-mediated" adverse effects and only a small subset (about $20 \%-30 \%$ ) has shown a treatment response to date, numerous clinical trials are ongoing. Further studies are needed to investigate the effectiveness of combined therapies, resistance mechanisms, predictive biomarkers, and the optimal management of adverse effects when using immunotherapies to treat lung cancer.

\section{Authors' Contributions}

Conceptualization: Choi CM. Writing - original draft preparation: Kim HC. Writing - review and editing: Choi CM. Approval of final manuscript: all authors.

\section{Conflicts of Interest}

No potential conflict of interest relevant to this article was reported. 


\section{Funding}

No funding to declare.

\section{References}

1. Simunovic N, Devereaux PJ, Sprague S, Guyatt GH, Schemitsch E, Debeer J, et al. Effect of early surgery after hip fracture on mortality and complications: systematic review and meta-analysis. CMAJ 2010;182:1609-16.

2. Kim HC, Jung CY, Cho DG, Jeon JH, Lee JE, Ahn JS, et al. Clinical characteristics and prognostic factors of lung cancer in Korea: a pilot study of data from the Korean Nationwide Lung Cancer Registry. Tuberc Respir Dis 2019;82:118-25.

3. Kim YC, Won YJ. The Development of the Korean Lung Cancer Registry (KALC-R). Tuberc Respir Dis 2019;82:91-3.

4. Park JY, Jang SH. Epidemiology of lung cancer in Korea: recent trends. Tuberc Respir Dis 2016;79:58-69.

5. National Lung Screening Trial Research Team, Aberle DR, Adams AM, Berg CD, Black WC, Clapp JD, et al. Reduced lung-cancer mortality with low-dose computed tomographic screening. N Engl J Med 2011;365:395-409.

6. Kan Z, Jaiswal BS, Stinson J, Janakiraman V, Bhatt D, Stern $\mathrm{HM}$, et al. Diverse somatic mutation patterns and pathway alterations in human cancers. Nature 2010;466:869-73.

7. Kobayashi S, Boggon TJ, Dayaram T, Janne PA, Kocher O, Meyerson M, et al. EGFR mutation and resistance of nonsmall-cell lung cancer to gefitinib. N Engl J Med 2005;352:78692.

8. Solomon BJ, Mok T, Kim DW, Wu YL, Nakagawa K, Mekhail $\mathrm{T}$, et al. First-line crizotinib versus chemotherapy in ALKpositive lung cancer. N Engl J Med 2014;371:2167-77.

9. Lee SH. Chemotherapy for lung cancer in the era of personalized medicine. Tuberc Respir Dis 2019;82:179-89.

10. Jackman D, Pao W, Riely GJ, Engelman JA, Kris MG, Janne PA, et al. Clinical definition of acquired resistance to epidermal growth factor receptor tyrosine kinase inhibitors in nonsmall-cell lung cancer. J Clin Oncol 2010;28:357-60.

11. Forde PM, Kelly RJ, Brahmer JR. New strategies in lung cancer: translating immunotherapy into clinical practice. Clin Cancer Res 2014;20:1067-73.

12. Brahmer JR, Pardoll DM. Immune checkpoint inhibitors: making immunotherapy a reality for the treatment of lung cancer. Cancer Immunol Res 2013;1:85-91.

13. D'Incecco A, Andreozzi M, Ludovini V, Rossi E, Capodanno A, Landi L, et al. PD-1 and PD-L1 expression in molecularly selected non-small-cell lung cancer patients. Br J Cancer 2015; 112:95-102.

14. Pardoll DM. The blockade of immune checkpoints in cancer immunotherapy. Nat Rev Cancer 2012;12:252-64.

15. Chen DS, Mellman I. Oncology meets immunology: the cancer-immunity cycle. Immunity 2013;39:1-10.
16. Jung CY, Antonia SJ. Tumor immunology and immune checkpoint inhibitors in non-small cell lung cancer. Tuberc Respir Dis 2018;81:29-41.

17. Chen DS, Mellman I. Elements of cancer immunity and the cancer-immune set point. Nature 2017;541:321-30.

18. Fife BT, Bluestone JA. Control of peripheral T-cell tolerance and autoimmunity via the CTLA-4 and PD-1 pathways. Immunol Rev 2008;224:166-82.

19. Buchbinder EI, Desai A. CTLA-4 and PD-1 pathways: similarities, differences, and implications of their inhibition. Am J Clin Oncol 2016;39:98-106.

20. Keir ME, Butte MJ, Freeman GJ, Sharpe AH. PD-1 and its ligands in tolerance and immunity. Annu Rev Immunol 2008; 26:677-704.

21. Konishi J, Yamazaki K, Azuma M, Kinoshita I, Dosaka-Akita H, Nishimura M. B7-H1 expression on non-small cell lung cancer cells and its relationship with tumor-infiltrating lymphocytes and their PD-1 expression. Clin Cancer Res 2004;10: 5094-100.

22. Nomi T, Sho M, Akahori T, Hamada K, Kubo A, Kanehiro H, et al. Clinical significance and therapeutic potential of the programmed death-1 ligand/programmed death-1 pathway in human pancreatic cancer. Clin Cancer Res 2007;13:2151-7.

23. Hamanishi J, Mandai M, Iwasaki M, Okazaki T, Tanaka Y, Yamaguchi K, et al. Programmed cell death 1 ligand 1 and tumor-infiltrating CD8+ T lymphocytes are prognostic factors of human ovarian cancer. Proc Natl Acad Sci U S A 2007;104: 3360-5.

24. Zielinski C, Knapp S, Mascaux C, Hirsch F. Rationale for targeting the immune system through checkpoint molecule blockade in the treatment of non-small-cell lung cancer. Ann Oncol 2013;24:1170-9.

25. Borghaei H, Paz-Ares L, Horn L, Spigel DR, Steins M, Ready $\mathrm{NE}$, et al. Nivolumab versus docetaxel in advanced nonsquamous non-small-cell lung cancer. N Engl J Med 2015;373: $1627-39$.

26. Brahmer J, Reckamp KL, Baas P, Crino L, Eberhardt WE, Poddubskaya E, et al. Nivolumab versus docetaxel in advanced squamous-cell non-small-cell lung cancer. N Engl J Med 2015; 373:123-35.

27. Herbst RS, Baas P, Kim DW, Felip E, Perez-Gracia JL, Han JY, et al. Pembrolizumab versus docetaxel for previously treated, PD-L1-positive, advanced non-small-cell lung cancer (KEYNOTE-010): a randomised controlled trial. Lancet 2016;387: 1540-50.

28. Rittmeyer A, Barlesi F, Waterkamp D, Park K, Ciardiello F, von Pawel J, et al. Atezolizumab versus docetaxel in patients with previously treated non-small-cell lung cancer (OAK): a phase 3 , open-label, multicentre randomised controlled trial. Lancet 2017;389:255-65.

29. Carbone DP, Reck M, Paz-Ares L, Creelan B, Horn L, Steins M, et al. First-line nivolumab in stage IV or recurrent non-smallcell lung cancer. N Engl J Med 2017;376:2415-26. 
30. Reck M, Rodriguez-Abreu D, Robinson AG, Hui R, Csoszi T, Fulop A, et al. Pembrolizumab versus chemotherapy for PD-L1-positive non-small-cell lung cancer. N Engl J Med 2016; 375:1823-33.

31. Mok TS, Wu YL, Kudaba I, Kowalski DM, Cho BC, Turna HZ, et al. Pembrolizumab versus chemotherapy for previously untreated, PD-L1-expressing, locally advanced or metastatic non-small-cell lung cancer (KEYNOTE-042): a randomised, open-label, controlled, phase 3 trial. Lancet 2019;393:181930.

32. Galluzzi L, Buque A, Kepp O, Zitvogel L, Kroemer G. Immunological effects of conventional chemotherapy and targeted anticancer agents. Cancer Cell 2015;28:690-714.

33. Apetoh L, Ladoire S, Coukos G, Ghiringhelli F. Combining immunotherapy and anticancer agents: the right path to achieve cancer cure? Ann Oncol 2015;26:1813-23.

34. Gandhi L, Rodriguez-Abreu D, Gadgeel S, Esteban E, Felip E, De Angelis F, et al. Pembrolizumab plus chemotherapy in metastatic non-small-cell lung cancer. N Engl J Med 2018;378: 2078-92.

35. Paz-Ares L, Luft A, Vicente D, Tafreshi A, Gumus M, Mazieres J, et al. Pembrolizumab plus chemotherapy for squamous nonsmall-cell lung cancer. N Engl J Med 2018;379:2040-51.

36. Socinski MA, Jotte RM, Cappuzzo F, Orlandi F, Stroyakovskiy D, Nogami N, et al. Atezolizumab for first-line treatment of metastatic nonsquamous NSCLC. N Engl J Med 2018;378: 2288-301.

37. Horn L, Mansfield AS, Szczesna A, Havel L, Krzakowski M, Hochmair MJ, et al. First-line atezolizumab plus chemotherapy in extensive-stage small-cell lung cancer. N Engl J Med 2018;379:2220-9.

38. Forde PM, Chaft JE, Smith KN, Anagnostou V, Cottrell TR, Hellmann MD, et al. Neoadjuvant PD-1 blockade in resectable lung cancer. N Engl J Med 2018;378:1976-86.

39. Cottrell TR, Thompson ED, Forde PM, Stein JE, Duffield AS, Anagnostou V, et al. Pathologic features of response to neoadjuvant anti-PD-1 in resected non-small-cell lung carcinoma: a proposal for quantitative immune-related pathologic response criteria (irPRC). Ann Oncol 2018;29:1853-60.

40. Gobbini E, Giaj Levra M. Is there a room for immune checkpoint inhibitors in early stage non-small cell lung cancer? J Thorac Dis 2018;10(Suppl 13):S1427-37.

41. Antonia SJ, Villegas A, Daniel D, Vicente D, Murakami S, Hui R, et al. Durvalumab after chemoradiotherapy in stage III nonsmall-cell lung cancer. N Engl J Med 2017;377:1919-29.

42. Postow MA, Sidlow R, Hellmann MD. Immune-related adverse events associated with immune checkpoint blockade. N Engl J Med 2018;378:158-68.

43. Michot JM, Bigenwald C, Champiat S, Collins M, Carbonnel
F, Postel-Vinay S, et al. Immune-related adverse events with immune checkpoint blockade: a comprehensive review. Eur J Cancer 2016;54:139-48.

44. Abdel-Wahab N, Shah M, Suarez-Almazor ME. Adverse events associated with immune checkpoint blockade in patients with cancer: a systematic review of case reports. PLoS One 2016;11:e0160221.

45. Wang PF, Chen Y, Song SY, Wang TJ, Ji WJ, Li SW, et al. Immune-related adverse events associated with anti-PD-1/PDL1 treatment for malignancies: a meta-analysis. Front Pharmacol 2017;8:730.

46. Naidoo J, Wang X, Woo KM, Iyriboz T, Halpenny D, Cunningham J, et al. Pneumonitis in patients treated with antiprogrammed death-1/programmed death ligand 1 therapy. J Clin Oncol 2017;35:709-17.

47. Suresh K, Naidoo J, Lin CT, Danoff S. Immune checkpoint immunotherapy for non-small cell lung cancer: benefits and pulmonary toxicities. Chest 2018;154:1416-23.

48. Friedman CF, Proverbs-Singh TA, Postow MA. Treatment of the immune-related adverse effects of immune checkpoint inhibitors: a review. JAMA Oncol 2016;2:1346-53.

49. Brahmer JR, Lacchetti C, Schneider BJ, Atkins MB, Brassil KJ, Caterino JM, et al. Management of immune-related adverse events in patients treated with immune checkpoint inhibitor therapy: American Society of Clinical Oncology Clinical Practice Guideline. J Clin Oncol 2018;36:1714-68.

50. Sharma P, Hu-Lieskovan S, Wargo JA, Ribas A. Primary, adaptive, and acquired resistance to cancer immunotherapy. Cell 2017;168:707-23.

51. Jenkins RW, Barbie DA, Flaherty KT. Mechanisms of resistance to immune checkpoint inhibitors. Br J Cancer 2018;118: 9-16.

52. Pitt JM, Vetizou M, Daillere R, Roberti MP, Yamazaki T, Routy $\mathrm{B}$, et al. Resistance mechanisms to immune-checkpoint blockade in cancer: tumor-intrinsic and -extrinsic factors. Immunity 2016;44:1255-69.

53. Pu X, Wu L, Su D, Mao W, Fang B. Immunotherapy for nonsmall cell lung cancers: biomarkers for predicting responses and strategies to overcome resistance. BMC Cancer 2018;18: 1082.

54. De Henau O, Rausch M, Winkler D, Campesato LF, Liu C, Cymerman DH, et al. Overcoming resistance to checkpoint blockade therapy by targeting PI3Kgamma in myeloid cells. Nature 2016;539:443-7.

55. Newick K, O'Brien S, Moon E, Albelda SM. CAR T cell therapy for solid tumors. Annu Rev Med 2017;68:139-52.

56. Miliotou AN, Papadopoulou LC. CAR T-cell therapy: a new era in cancer immunotherapy. Curr Pharm Biotechnol 2018; 19:5-18. 